\title{
1 Effect of human activity on habitat selection in the endangered Barbary macaque
}

2

3 James O. Waterman ${ }^{1,2}$, Liz A.D. Campbell ${ }^{1,3}$, Laëtitia Maréchal ${ }^{1}$, Malgorzata Pilot ${ }^{4,5}$ \&

4 Bonaventura Majolo ${ }^{1 *}$

5

61 School of Psychology, University of Lincoln, Brayford Wharf East, Lincoln, LN5 7AY, United

$7 \quad$ Kingdom

82 School of Natural Sciences \& Psychology, Liverpool John Moores University, Byrom Street,

9 Liverpool, L3 3AF, United Kingdom

103 WildCRU, University of Oxford, Recanti-Kaplan Centre, Abingdon Road, Tubney, OX13 5QL,

11 United Kingdom

124 School of Life Sciences, University of Lincoln, Beevor Street, Lincoln, LN6 7DL, United

13 Kingdom

145 Museum and Institute of Zoology, Polish Academy of Sciences, ul. Nadwiślańska 108, 80-680

15 Gdańsk, Poland

16

17

$18 *$ Correspondence author: Bonaventura Majolo, School of Psychology, University of Lincoln,

19 Brayford Wharf East, Lincoln, LN5 7AY, UK. Phone: +44-01522-837015; email:

20 bmajolo@lincoln.ac.uk

21

22 Short title: Barbary macaque habitat selection 
Abstract:

24 The exponential growth of human population and infrastructure is significantly reducing the amount

25 of ecological resources available for wild animals. We analyzed the effect of human activity on Barbary macaques (Macaca sylvanus), an endangered species restricted to the fragmented forests of Morocco and Algeria, using location data from five social groups inhabiting Ifrane National Park, Morocco.

We used a resource selection function to explore the effects of anthropogenic disturbance on macaque habitat selection, using nine natural, social, and anthropogenic disturbance variables as

31 predictors. Forest cover, home range overlap, herding route proximity, and road proximity were all significant predictors of habitat use. Macaques avoided areas used by local shepherds, to reduce the risk of attack by shepherds' dogs, but approached roads to increase the chances of provisioning by tourists. However, herding route and road use varied seasonally in line with levels of human use, suggesting that macaques may be navigating their environment strategically (in space and time) to balance food acquisition and risk avoidance. The results of this study highlight the importance of assessing human impact on habitat selection in both space and time. Our data on seasonal variations in macaques' use of roads can help prevent road injuries, a major source of mortality for provisioned macaques, by focusing management efforts by national park workers in time and space.

40 Furthermore, understanding when and where macaques seek provisioning from tourists can help 41 combat provisioning, which negatively impacts macaque health, behavior, and susceptibility to poaching.

Keywords: dog-wildlife interactions; ecological niche; home-range use; human disturbance; primate conservation; resource selection. 


\section{INTRODUCTION}

Human activities have altered the environmental conditions of every biome on the planet (Ellis \& Ramankutty, 2008). As landscapes become increasingly human-dominated, many wildlife species must cope with new ecological pressures (Woodroffe, Thirgood, \& Rabinowitz, 2005). The impact of habitat loss/fragmentation, climate change, expanding human infrastructure, hunting, and poaching quickly and dramatically alters habitats, forcing wildlife to adjust, move to more suitable areas (if these are available), or face the threat of extinction (Sih, Ferrari, \& Harris, 2011). The species that persist in human dominated landscapes adapt to anthropogenic habitats by modifying their behavior and some invasive and urbanized species (i.e. species that live in habitats that are outside their typical ecological niche, often at high densities) even prosper in dramatically altered habitats (Lowry, Lill, \& Wong, 2013).

Animals may alter their habitat use to avoid areas of intense human activity (spatial avoidance) (Gill, 2000; Guillemain et al., 2007) and/or use those areas only when human activity is low (temporal avoidance). For example, carnivores avoid areas used intensively by humans or only use/move through those areas when human activity is low (Hebblewhite \& Merrill, 2008; Martin et al., 2010; Bouyer et al., 2015; Oriol-Cotterill et al., 2015). A meta-analysis examining diel patterns in 62 mammal species found a strong, positive effect of human activity on nocturnality (Gaynor et al., 2018). A study of the activity patterns in cathemeral Eulemur species found that lemurs in more disturbed areas exhibited more nocturnal activity than those in less disturbed areas (Donati et al., 2016).

Risk perception can significantly influence habitat use. Many species demonstrate great flexibility in adapting their behavior according to the risks (from natural predators or humans) associated with particular areas of their range, and at particular times (Frid \& Dill, 2002; Hockings, Anderson, \& Matsuzawa, 2012; Coleman \& Hill, 2014; Bryson-Morrison et al., 2017; Nowak et al., 2017). However, risky areas and certain human activities can provide short-term benefits to 
wildlife, such as predator deterrence and/or feeding opportunities (e.g. refuse sites, roadside provisioning and farming) (Gilchrist \& Otali, 2002; McKinney, 2011). Animals may specifically select risky, but profitable, areas when the cost-benefit balance is most strongly in their favor, i.e. at times likely to yield greater rewards at lower potential costs (Hockings, Anderson, \& Matsuzawa, 2012; Maréchal, MacLarnon, et al., 2016). For example, chimpanzees frequently forage on crops at night to minimize the risk of detection by human guards (Krief et al., 2014). Such flexibility allows animals to adapt to local risk/reward conditions by balancing the potential benefits of provisioning or acquisition of other resources, against the potential risk of predation, capture, or other negative consequences.

The capacity of wildlife to be flexible in their habitat selection depending on the timing, intensity, and type of human influence has been under-investigated (Beyer et al., 2010; Wilson, Gilbert-Norton, \& Gese, 2012; but see Bryson-Morrison et al., 2017). Such fine-scale assessments are important because they can help to inform land-use planning that minimizes the potential for human-wildlife conflict. Our aim was to assess if and how animals adjust and respond to the new ecological pressures of human-dominated landscapes, using the endangered Barbary macaque reported incidences of dogs taking Barbary macaque infants (Camperio Ciani \& Mouna, 2006) and 
Several roads also run through the study site (both North to South, and East to West), one of which is a major transport route towards the Sahara desert in the South (Fig. 1). At two locations along this road, tourist sites were constructed where local vendors sell fossils and other souvenirs to tourists that come to see the macaques. Originally, the vendors fed these macaques to encourage them to remain visible near the roadside and attract tourists. At the time of the study, two groups of macaques ( 1 of which was included in this study) regularly spent the majority of the day in and around these sites, whether provisioned by vendors or not. The direct and indirect effects of pastoralist activity, in combination with the illegal trade of infant macaques to Europe, have driven a dramatic decline in wild population numbers in recent decades. Although a few studies have investigated the effects of anthropogenic activity on Barbary macaques (Ménard et al., 2014; Maréchal, MacLarnon, et al., 2016; Carne et al., 2017), none has examined the extent to which human activity influences macaque habitat selection. Such information can be used to direct conservation efforts and resources to the issues that warrant the most attention and/or the most immediate action.

The macaque population in Morocco experiences strong seasonal variations in climate (Majolo et al., 2013), and thus resource availability (Hanya et al., 2011), requiring the Barbary macaque to be an eclectic forager and dietary generalist (Ménard, 2002). These seasonal variations also influence how easily accessible the forest is to local people. For example, during periods of heavy snowfall, shepherds and dogs tend to remain at low elevations with their livestock, and the forest herding routes are relatively quiet. We examined the habitat preferences of five wild groups of Barbary macaques in Morocco across four seasons. The study groups often encountered shepherds and their dogs, and crossed roads. The use of roads by macaques can be both beneficial and risky (Maréchal, MacLarnon, et al., 2016). Roads provide opportunities for macaques to acquire calorie-dense human food from tourists, but also pose a serious threat from vehicle collisions (Campbell et al., 2016; Campbell, 2019). Many large-brained, long-lived animals, like primates, 
121 achieve local adaptation to rapidly changing environmental conditions through behavioral

122 flexibility. They are likely to have many opportunities for social learning, through long parent-

123 offspring association, and strong social-learning abilities (Schaik, 2013). This scenario applies to

124 our study species: Barbary macaques display high behavioral flexibility and great ecological

125 plasticity, adapting well across habitat types and seasons (Ménard, 2002). As such, we hypothesized

126 that macaques would display spatial and temporal flexibility in the use of their home ranges, based

127 on a cost/benefit analysis of the different areas used, or available for use. We analyzed how these

128 preferences related to the type and intensity of human activity within their home ranges, habitat

129 productivity, forest cover, slope, and position within the home range. We predicted that macaques

130 (1) would avoid risky areas, that is, herding routes where sheep dogs are abundant and escape

131 possibilities scarce (because of the absence of tree cover) and (2) would do so especially at high-

132 risk times (e.g. when herding routes are most heavily used - spring and summer). We also predicted

133 that macaques (3) would use the most profitable areas within their home ranges (e.g. roads, or

134 highly productive areas) and (4) particularly so when the potential benefits outweigh the risks, i.e.

135 when natural food is scarce.

137 METHODS

138 Study area and subjects

139 Our study was conducted in Ifrane National Park (INP) in the Middle Atlas Mountains of Morocco

$140\left(33^{\circ} 25^{\prime} \mathrm{N}, 005^{\circ} 10^{\prime} \mathrm{W}\right)$, from May 2013 to April 2014 (Fig. 1). The study area is covered by

141 deciduous Atlas cedar and mixed oak (Quercus ilex and Quercus faginea) forest with patches of 142 open scrubland.

143 We collected data on 54 adult ( $>4$ years old) and 17 subadult monkeys from five groups of

144 Barbary macaques (Supplementary Material S1). The study animals were tolerant of researchers

145 (Bejder et al., 2009) and individually identified. Monkeys in one group received food from tourists 
and local people at least once per day; the other groups were occasionally provisioned by tourists.

Data collection was entirely non-invasive. We complied with the International Primatological Society's ethical guidelines for primate field research and received research permission (number 08/2013) from the Haut Commisariat des Eaux et Forêts et à la Lutte Contre la Désertification of Morocco.

\section{Data collection}

\section{Home range estimation}

We estimated the home ranges of the study groups using Brownian Bridge Movement Models (BBMM). This method accounts for the temporal correlation of locations recorded over brief intervals, and incorporates known estimates of location error to predict trajectories of movement between successive locations (Horne et al., 2007). This quantifies the utilization distribution (UD) parameter of a group/animal based on its path rather than on individual points. Behavioral observations were carried out for five to seven days each week from 06:00 to 19:00 (mean daily observation hours $\pm \mathrm{SE}=9.20 \pm 0.19$ ). Each day, different teams of observers followed between one and four (usually three) groups, simultaneously. We took global positioning system (GPS) readings every 60 minutes at the center of the group using a Garmin etrex Summit HC (CGarmin). We estimated the center of the group as the point in the middle of an imagined ellipse around all visible group members. This yielded a total of 1935 GPS locations over 171 working days (total number of GPS locations per group: Blue group $=355$, Green group $=499$, Purple group $=468$, Red group $=230$, Yellow group $=383$ ). We analyzed home range data in R version 3.5.3 (R Core Team, 2019) using the BBMM package (Nielson \& Sawyer, 2013). Each group's home range overlapped with at least one other group, was crossed by a road, and included at least one type of human structure (i.e., picnic area, water treatment plant, livestock stable and/or a small farm) (Fig. $1)$. 
173 To estimate the changing seasonal intensity of human road and herding route use, we placed fifteen $174900 \mathrm{~m}$ straight-line transects throughout the study area, according to a stratified random sampling 175 design (Ganzhorn, 2003). The original sampling area was based on home range data for two 176 macaque groups identified during previous studies in the area (The Barbary Macaque Project, 177 University of Lincoln, UK). The furthest extent of these groups' home ranges determined the 178 easterly and westerly extent of the study area, and the edge of the forest fragment determined the 179 northerly and southerly extent. We determined the transects spacing and orientation using the 180 software Distance 6.0 release 2 (Thomas et al., 2010). Any transects that were later found to be 181 outside the home ranges of our five study groups were dropped. We walked the transects at 182 different times of day, starting at a different end each time, once every 2 weeks, and recorded all 183 sightings of humans, livestock, dogs, and motor vehicles (hereafter HRS, 'human related sighting'). 184 We used identifiable features (e.g. clothes worn by shepherds or dog breeds) of each HRS to distinguish them and avoid repeat recordings within transects. If we encountered the same HRS more than once on the same transect within the same sampling period, we only recorded the first 187 sighting. We walked each transect 24 times (three transects were walked 23 times), for a total of $18821.6 \mathrm{~km}$ and $20.7 \mathrm{~km}$, respectively, per transect. The total transect distance walked was $2222.1 \mathrm{~km}$ 189 and the total observation time was 312.15 hours. Where transects crossed a road, we recorded the 190 number of vehicles that passed within five minutes of reaching it. We conducted 307 road counts 191 for a total observation time of 25.6 hours.

\section{Ecological data}

194 We derived Normalized Difference Vegetation Index (NDVI) values from Landsat 8 satellite 195 images of the study area, obtained from the USGS EarthExplorer website (U.S. Geological Survey 
196 Earth Resources Observation and Science Center, 2012). These data were used to assess ecological 197 productivity by season (Myneni et al., 1995; Wang et al., 2005). Monthly NDVI rasters were the 198 mean of two satellite images per month, and seasonal NDVI rasters were the mean of three monthly 199 rasters per season. NDVI quantifies the density of plant growth and is calculated by comparing the 200 quantities of visible and near-infrared light reflected by vegetation. Unhealthy or sparse vegetation 201 reflects more visible light and less near-infrared light than thriving or dense vegetation.

\section{Data Analysis}

204 We used a resource selection function (RSF) to examine the predicted probability of use (PPU) of an area by a group. A RSF is defined as any function that yields values proportional to the probability of use of a resource unit by an organism (Manly et al., 2002). The units being selected by animals (e.g. pixels of land) are conceived as resources. Predictor variables associated with these resource units may be 'resource' variables or covariates of the resources, e.g. elevation or humandisturbance. Logistic regression is commonly used to estimate habitat selection models with used units (e.g. pixels of land in a geographic information system (GIS) model) characterized as

211 1, and unused (or available) units characterized as 0 (Boyce et al., 2002). We measured resource 212 use and availability separately for each group (Thomas \& Taylor, 1990). We defined the available 213 area as that within a group's 95\% BBMM home range. To assess the relative influence of 214 anthropogenic, natural, and social landscape characteristics on the probability of a group using an 215 area, we included nine variables (Table 1) and two interaction terms (detailed below) as predictors 216 in the RSF.

\section{Anthropogenic features}

219 To analyze whether macaques altered habitat selection in relation to anthropogenic features, we 220 calculated the distance from herding routes and roads to every macaque location (used and 
available), using the 'Proximity (Raster Distance)' tool in the SAGA (2.3.2) toolbox in QGIS 3.6.0

(Open Source Geospatial Foundation, 2019). We added the length of herding routes and roads per $\mathrm{km}^{2}$ within each group's home range to the RSF as control variables to account for the differing densities of anthropogenic features and undisturbed areas experienced by each group. Because the intensity of herding route and road use by humans vary throughout the year (largely in line with temperature, snowfall, and thus accessibility), we included interaction terms between distance to herding routes and season, and distance to roads and season to examine whether macaques employ temporal as well as spatial habitat selection in response to anthropogenic features. We used general linear models to compare herding route activity and traffic volume by season, and Post hoc Tukey's least significance difference (LSD) tests to compare activity/volume between seasons.

\section{Natural landscape features}

Barbary macaques are known to avoid open areas, due to a lack of opportunities to climb trees when threatened by dogs or other predators (Ménard, 2002; Ciani et al., 2005; Maréchal, Semple, et al., 2016; Waterman, 2016). Therefore, we created a digitized map of forest cover type, collapsed into three classes: dense (50\%-100\% tree cover), moderate (1\%-49\% tree cover), and open (no tree cover). We estimated cover type from a satellite map of the study area and ground-truthed using canopy cover, undergrowth density and abundance data, and routine mapping data collected during the study. Next, we analyzed the effect of food distribution on habitat use (Lima \& Dill, 1990). For this purpose, we averaged NDVI cell values (cell size $30 \mathrm{~m}^{2}$ ) by season to create productivity raster maps of the study area (one for each of our five study seasons). The NDVI values of all used and available points were drawn from the appropriate raster, i.e. the seasonal raster in which the data were collected. We used a general linear model to compare NDVI values by season, and post-hoc Tukey's LSD tests to compare NDVI between seasons. Because Barbary macaques live in a mountainous habitat, we derived slope data from Advanced Spaceborne Thermal Emission 
Reflection Radiometer (ASTER) - Global Digital Elevation Model (GDEM) data (obtained from the USGS Earth Data website; U.S. Geological Survey, 2015), and incorporated it as a 1 arc-second

248 (approximately $30 \mathrm{~m}^{2}$ ) grid (Toutin, 2008). High values correspond to steep gradients, low values to 249 shallow gradients, and zero values to primarily flat terrain.

\section{Social features}

Barbary macaque home ranges commonly overlap . Therefore, we used the 'kerneloverlap' command of the 'adehabitatHR' (Calenge, 2006) package in R version 3.5.3 to calculate 95\% utilization distribution overlap index values (UDOI) for each pair of groups, across the entire study period, and by season (Fieberg \& Kochanny, 2005). Values of UDOI $<1$ indicate less overlap relative to uniform space use, whereas values of UDOI > 1 indicate higher than normal overlap relative to uniform space use. Because home range overlap can affect the intensity and timing of use of an area (R. W. Wrangham et al., 2007), we included a binary measure (overlapping or not) to the RSF to describe whether each used or available location was within the 95\% BBMM home range of more than one group. This was calculated by season for each group (spring 2013 through spring 2014), e.g. locations recorded in summer 2013 were only tested for overlap with the home ranges of other groups derived from their summer 2013 home range estimates. We used linear mixed models

263 (LMMs), including random intercepts for group and season, to compare NDVI values, the distance 264 to herding routes, and the distance to roads by overlap status (overlapping or not). No post-hoc tests were required to interpret these results.

\section{Statistical models}

268 We constructed a GIS model of the study area using QGIS. We imported GPS locations and 269 generated 10 random locations (within the appropriate home range) per observed location to create an 'available' sample. We restricted observed and random locations to within 95\% BBBM home 
ranges because most macaque activity was restricted to these areas and it is difficult to objectively define an 'available' area outside a group's home range (Wilson, Gilbert-Norton, \& Gese, 2012). We used logistic regression to estimate a RSF by comparing anthropogenic, natural and social landscape features of used and available locations for each individual. We used a generalized linear mixed model with binary response variable $(1=$ used, $0=$ available but unused $)$, binomial error distribution, and logit link to evaluate habitat selection. We included a random intercept for group to account for correlation of habitat use within group, and uncorrelated random intercepts and slopes for distance to herding routes, and distance to roads within group. These were included to account for the fact that groups had varying baselines of distance from these features, i.e. some groups had little un-disrupted space compared to others. Moreover, we used this method to account for the fact that groups would likely respond to herding route and road proximity differently (in terms of selecting/avoiding areas), e.g. some groups may select roadsides whilst others avoid them. We fitted the RSF using the 'glmer' command of the 'Ime4' package (Bates, 2010) in R version 3.5.3 (R Core Team, 2019) and estimated the GLMM parameters using Laplace approximation (Bolker et al., 2009). We used a full model approach throughout. We checked the model for collinearity between predictors using generalized variance inflation factors, which indicated no issues of collinearity (average $\operatorname{GVIF}^{\wedge}(1 /(2 * \mathrm{Df}))$ score $=1.31$, maximum $\operatorname{GVIF}^{\wedge}(1 /(2 * \mathrm{Df}))$ score $=$ 2.00) (Fox \& Monette, 1992). We standardized all distance-based variables. Because of the difficulty in defining the denominator degrees of freedom in mixed models (Luke, 2017) (i.e. does one count the number of observations, or the number of subjects and/or items, or the number of random effects, or some combination of these?), we determined the significance of the fixed effects using likelihood-ratio tests ("mixed" function in the package "afex" (Singmann et al., 2017)). We fitted full and restricted models (models in which the parameter of interest, the fixed effect, are withheld, i.e. fixed to 0) and based test statistics on comparisons of the full model with the restricted models. The significance of the likelihood ratio test statistic is 
calculated using a $\chi^{2}$ distribution with the appropriate degrees of freedom. All statistical tests were

297 two-tailed with $\alpha$ set to 0.05 . We examined the residuals of all relevant models for normality and 298 homoscedasticity and detected no problems. We carried out model validation using $k$-fold $(k=10)$ 299 cross-validation, testing predictive performance using area under the curve (AUC) (Boyce et al., 300 2002). We classified models as: 1 ) non-informative (AUC $=0.5) ; 2)$ less accurate $(0.5<\mathrm{AUC} \leq 0.7) ; 3$ ) 301 moderately accurate $(0.7<\mathrm{AUC} \leq 0.9)$; 4$)$ highly accurate $(0.9<\mathrm{AUC}<1)$; and 5$)$ perfect $(\mathrm{AUC}=1)$ 302 (Swets, 1988). For further model validation we also calculated the GLMM dispersion parameter 303 when relevant. For a step-by-step summary of the data analysis procedure see Supplementary 304 Material S2.

\section{RESULTS}

307 Barbary macaques showed temporal and spatial habitat selection in relation to anthropogenic 308 features (Tables 2-4): They avoided herding routes and selected/avoided areas close to roads, but 309 this behavior varied seasonally. They also preferred overlapping areas of their home ranges, and 310 avoided open areas. AUC values indicated that the RSF model was 'less accurate' and close to 311 being classified as 'moderately accurate' (AUC=0.66). The GLMM dispersion parameter value was 3121.05.

Mean NDVI, herding route activity, and traffic volume differed significantly between 314 seasons (NDVI general linear model: $F(3,20720)=7611.9, p<0.001$, marginal $\mathrm{R}^{2}=0.52$. Herding 315 route activity general linear model: $F(3,20720)=762.1, p<0.001$, marginal $\mathrm{R}^{2}=0.10$. Traffic volume 316 general linear model: $F(3,20720)=210.7, p<0.001$, marginal $\left.\mathrm{R}^{2}=0.03\right)$. Post hoc LSD tests showed 317 that mean NDVI, herding route activity, and traffic volume differed significantly between all four 318 seasons (all $p<0.001$ ). Most notably, in autumn and winter, NDVI and herding route activity were 319 lowest whilst road traffic volume peaked (Fig. 2a, b, c). 

significantly between areas of exclusive and overlapping home range use (overlaps derived using seasonal home range estimates, see above; NDVI linear mixed model: $F(1,1930.2)=4.0181, p=0.04$; distance to herding routes linear mixed model: $F(1,1928.8)=11.978, p<0.001$; distance to roads linear mixed model: $F(1,1931.9)=34.921,<0.0001$; Fig. 3a, b, c).

The UDOI of macaque $95 \%$ home ranges indicated that all pairs of groups showed less overlap than would be expected from wholly overlapping distributions at 95\% contour levels (Table 5). In autumn and winter only the green-purple group pair showed any overlap. The winter UDOI was the highest recorded throughout the study.

Overall, macaques selected dense and moderately forested areas, and avoided open areas. They preferred areas that overlapped the home ranges of neighboring groups. They avoided herding routes in summer and avoided areas close to roads in spring. The predicted probability of use (PPU) of areas close to herding routes in summer was almost half that of the other seasons. However, they used areas close to roads more extensively in autumn and winter months. The PPU of areas close to roads in autumn and winter was approximately double that of spring, and a third greater than in summer (Fig 4a and 4b).

\section{DISCUSSION}

338 Our study showed that Barbary macaques navigate their environment strategically in relation to 339 human activity, to balance food acquisition and risk avoidance. As predicted, macaques consistently 340 avoided open areas. This is likely a response to the limited escape possibilities, given that macaques 341 usually climb trees to avoid dogs, which are their primary predators at this study site (Waterman, 342 2016). This may explain why macaque density is lowest in open grassland areas, even though this 343 species feeds extensively on grass (Ménard, 2002; Ciani et al., 2005). The distribution of dogs 344 affects the use of space of pudu deer (Pudu puda) via both predation and avoidance mechanisms 
345 (Silva-Rodríguez \& Sieving, 2012); the space use patterns of Barbary macaques may be affected in 346 a similar way. Animals can assess the levels of predation risk in different parts of their habitat and 347 respond to them by modifying their spatial and temporal use of their home range and/or by 348 modifying behavior (e.g. increasing vigilance in high-risk areas). The spatial distribution of 349 predation risk perceived by a population of animals can be described as a "landscape of fear" 350 (Laundré, Hernández, \& Ripple, 2010). In such a "landscape of fear," animals should avoid areas 351 where the risk of encountering predators (i.e. the "degree of fear") is highest, unless using those 352 areas yield high rewards. For example, areas with high densities of predators may contain a large 353 amount of food if potential preys rarely feed in those areas. In human-dominated landscapes, human 354 disturbance may have a larger effect on the behavior of wild animals than their natural predators 355 (Ciuti et al., 2012). In the case of Barbary macaques, the direct effect of human disturbance is 356 amplified by the disturbance resulting from the presence of domestic dogs. Thus, for Barbary 357 macaques the "landscape of fear" can be determined by both the presence of predators (dogs) and of 358 human activities. Macaques preferentially used areas of home range overlap. It seems unlikely that macaques purposely select overlapping areas in general, but rather that they choose the most productive areas available to them. Given that these areas are on the periphery of groups' home-ranges, multiple 362 groups may try to make use of them. This usually takes place at different times, although numerous intergroup encounters were observed in direct relation to contested food sources within overlapping areas. This was particularly true during winter, when areas that contained hawthorn bushes and berries (Crataegus spp.) were contested by two of the study groups almost daily for several consecutive weeks. Considered together, the preference for overlapping areas indicated by the RSF, 367 and the relatively low UDOI values (Table 5) support the idea that macaques may attempt to use overlapping areas at different times. The UDOI takes into account the intensity of use of an area (by both groups) when assessing the extent of home-range overlap. This may be why the RSF indicates 
a preference for overlapping areas, despite the fact that the UDOI values indicate only limited

371 overlap. Although there may be few areas of actual overlap (low UDOI values, but see winter 2013-

372 2014), groups showed a strong preference for these, and seemed willing to share them, and/or

373 compete over them. Neighboring groups of Barbary macaques are known to use the same sleeping

374 sites located in areas of home range overlap and compete for these sleeping sites (Campbell,

375 Tkaczynski, Mouna, et al., 2018). It is also possible that the preference for overlapping areas was

376 driven by the large amount of time that some of the study groups spent waiting for provisioning by

377 the road within the shared portion of their home ranges. This is supported by the results of the

378 analysis comparing distance from roads by overlap status (see above): overlapping areas were, on

379 average, closer to roads than non-overlapping areas (Fig 3c).

These results suggest that macaques choose the most profitable areas available to them, even

381 if they overlap the home ranges of other groups. Few studies have focused on the effects of

382 neighboring groups on the behavior of primates, but in those that have, overlapping zones are

383 routinely reported to be under-used (R. W. Wrangham et al., 2007). A limited number of studies

384 have recorded primates making use of overlapping home range areas, but no consistent pattern of

385 use emerges. Verreaux's sifaka (Propithecus verreauxi) use overlapping zones, but their

386 behavioral patterns do not differ significantly from those observed in core areas (Benadi, Fichtel, \&

387 Kappeler, 2008). Aggressive intergroup encounters in some other species such as chimpanzees,

388 Diana monkeys (Cercopithecus diana), and Stuhlmann's blue monkeys (Cercopithecus mitis) can

389 result in the extensive wounding and even death of individuals (McGraw, Plavcan, \& Adachi-

390 Kanazawa, 2002; Payne, Lawes, \& Henzi, 2003; R. W. Wrangham, Wilson, \& Muller, 2006).

391 However, such lethal aggression between groups is rare in Barbary macaques (Deag, 1975). Thus,

392 Barbary macaques may perceive overlap zones as both high reward and low risk areas. This

393 hypothesis should be tested by examining, for example, duration of stay in overlap areas, selection

394 of food resources and of sleeping sites. 
The probability of macaques using areas close to herding routes varied seasonally. The PPU

396 in summer was approximately half that of spring, autumn, and winter (Fig 4a). This seasonal 397 reduction may be explained by the increased probability of encountering predators, particularly 398 dogs, in these areas during the busiest herding periods, i.e. the summer months. The probability of 399 macaques using areas close to roads also varied seasonally. The PPU in autumn and winter was 400 approximately double that of spring, and a third greater than that of summer (Fig 4b). In spring, 401 natural food (herbs, grasses, seeds etc.) is relatively abundant; however, the availability of natural 402 food in the study area declines steadily throughout the year as temperatures drop and winter 403 snowfall makes foraging difficult and energetically costly (Majolo et al., 2013). Winter is a time of 404 energetic deficit for Barbary macaques (Campbell, Tkaczynski, Lehmann, et al., 2018; Campbell, 405 Tkaczynski, Mouna, et al., 2018). This may shift the cost/benefit balance by making access to 406 energy-rich foods from tourists more valuable in autumn and winter: $38 \%$ of human-macaque 407 provisioning encounters in our study occurred within $20 \mathrm{~m}$ of a road (Waterman, 2016). This 408 consideration of energy balance affects selection of sleeping sites by Barbary macaques (Campbell, 409 Tkaczynski, Mouna, et al., 2018), and also their social behavior (Campbell, Tkaczynski, Lehmann, 410 et al., 2018), so diurnal habitat use (use of roads) may be another strategy to maximize energy 411 balance.

The benefit of accessing calorie-dense human food during food shortages may exceed the 413 cost associated with the risk of being injured/killed by road traffic (Campbell et al., 2016;

414 Campbell, 2019). Similar trade-offs in the use of roads have been observed in other primate species: 415 Long-tailed macaques (M. fascicularis) habitually consume human food near roads, and both the 416 number of groups and group size increase with proximity to roads and human settlements, despite 41735 road-accident deaths (2.4\% of the population) in one year (Mun, 2014). The combination of 418 roads and human provisioning is particularly deleterious for wild animals, since the risk of 
419 injuries/death, infectious human diseases, and diseases linked to a hyper-caloric diet is high, and its 420 reduction/avoidance should be a top priority for any conservation efforts. Chimpanzees adjust their behavior according to variations in the perceived risk of road

422 injuries, as they wait longer to cross wide roads than narrow ones, and wait longer on wide roads as 423 traffic volume increases (Hockings, Anderson, \& Matsuzawa, 2006). Barbary macaques appear to 424 follow a similar strategy: when roads are busy (and natural food is scarce) the potential rewards of 425 provisioning may outweigh the perceived risks; when roads are less busy (and/or natural food is 426 abundant) the potential rewards may be low enough that even a reduced risk is no longer worth the 427 reward. The fact that road traffic was highest in autumn (followed closely by winter) (Fig 2b), and 428 that $40 \%$ of our recorded human provisioning events occurred during winter (Waterman, 2016), 429 supports the idea that macaques engage in fine-scale behavioral adjustment in response to varying $430 \quad$ levels of perceived risk and reward.

The impact of human activity on the behavior of the Barbary macaque varies on a spatio432 temporal scale. The few remaining populations of this species occur in areas of relatively low 433 human density but high human impact, due to logging, farming and grazing (Scheffrahn et al., 434 1993; Ciani et al., 2005). As such, macaques are increasingly unable to avoid contact with humans 435 and must cope with greater constraints on their habitat choices. Macaques appear to deal with these 436 challenges in a very flexible way. They minimize risk by avoiding herding routes when they are 437 most trafficked (presumably to minimize the possibility of encountering dogs and humans), and 438 maximally exploit the potential of being provisioned near roads as a high-calorie food source. They 439 also preferentially use overlapping areas of their home ranges. However, this apparent preference 440 could be interpreted both as a response to the declining availability of suitable habitat/forage, 441 forcing macaque groups closer together, and/or a result of direct competition over particularly 442 profitable areas, e.g. roadside provisioning spots, patchy winter food sources, sleeping sites. Thus, 
even groups that only occasionally receive food from humans show a considerable degree of

444 habituation to human presence in the Middle Atlas Mountains of Morocco.

The opportunity exists to 'use' such habituation to develop eco-tourism programs that could benefit both the survival of this population and the local economy. However, our data also show that human activity in the area can significantly affect macaque behavior and habitat choices, with potentially dramatic consequences for their survival. Our conclusions are limited by the absence of 449 a fine-scale, on-the-ground measure of macaque food availability that spans the entire study area. 450 Although the NDVI values matched our ground productivity samples well, macaques are highly 451 flexible foragers and many of their preferred food items may not be well represented by NDVI, e.g. 452 acorns, fungi, and arthropods. Despite the significant logistical challenge of sampling ground453 productivity, at a fine scale, across such a large study area, future work could benefit from a full454 coverage ecological ground-sampling grid. This would allow us to more accurately assess the 455 influence of anthropogenic activity on macaque habitat selection, taking in to account the local availability of preferred macaque food items, and water sources.

Our study has identified two key spatio-temporal parameters that macaques 'prioritize' when selecting areas within their home ranges. This knowledge should be used to implement guidelines that sustain both a viable population of macaques and the local economy (Russon \& 460 Wallis, 2014). Due to the varying land uses, motivations, and social norms of people in contact with 461 the macaques, mitigating human-wildlife conflict in the region will require a holistic approach by 462 multiple stakeholders, including law enforcement, government, communities, and pastoralists. We 463 therefore recommend a baseline socio-demographic study of these stakeholders to identify their 464 attitudes, values, and behaviours. Rigorous social scientific survey design is essential in guiding, 465 monitoring and evaluating any social interventions effectively (St. John et al., 2014; Steg, 2016; 466 Rare and The Behavioural Insights Team, 2019). 
468 effect on macaque stress levels (Maréchal et al., 2011). Education stands in the area could provide 469 an opportunity to empower locals to become ambassadors for macaque conservation, with the 470 support of NGO's and government. A team of local Community Scouts currently works in Ifrane 471 National Park to prevent poaching, feeding, and road deaths of Barbary macaques (Campbell et al, 472 in review). Understanding the spatio-temporal variation in the approach vs. avoidance of humans 473 and roads by macaques can help the management of human-macaque interactions by prioritizing the 474 time and locations to focus these efforts. Our results indicate that efforts to combat feeding and road 475 deaths could be prioritized during autumn/winter. Identifying priorities where efforts are likely to be 476 most effective, especially if resources and funding for conservation management are limited, can 477 benefit conservation efforts. In conclusion, our findings highlight the importance of protecting 478 natural foraging areas for wildlife, particularly in areas where they come into contact with humans, 479 and regulating areas where wildlife has access to human food. 
481 ACKNOWLEDGEMENTS

482 We thank the Moroccan Haut Commissariat aux Eaux et Forêts et à la Lutte Contre le 483 Désertification for research permission (Authorisation Number 08/2013), and Professor Mohamed 484 Qarro for his help and support in the field. We are grateful to Ifrane National Park and the local 485 community for their support. We thank the following parks for a grant that funded this study: La 486 Montagne des Singes and La Foret des Singes (France), Affenberg Salem (Germany) and Trentham 487 Monkey Forest (Great Britain). We are grateful to Elina Rantanen, Brenda McGowan and two 488 anonymous reviewers for comments on an earlier draft of the manuscript. We thank Olivier 489 Mouchette, Barbora Kuběnová, Alice Marks, Vamsi Rani, Selma el Fassi Fihri, Camille Deman, 490 Callum Martin, Laura McHenry, Kevin Remeuf, Melanie LaCava, and Patrick Tkaczynski for their 491 help in data collection, and Corinne Bailey for advice on conservation strategies. 


\section{REFERENCES}

Bates, D. M. (2010). lme4: Mixed-effects modeling with R. Berlin.

Bejder, L., Samuels, A., Whitehead, H., Finn, H., \& Allen, S. (2009). Impact assessment research: use and misuse of habituation, sensitisation and tolerance in describing wildlife responses to anthropogenic stimuli. Mar. Ecol. Prog. Ser. 395, 177-185.

Benadi, G., Fichtel, C., \& Kappeler, P. (2008). Intergroup relations and home range use in Verreaux's sifaka ( Propithecus verreauxi ). Am. J. Primatol. 70, 956-965.

Beyer, H. L., Haydon, D. T., Morales, J. M., Frair, J. L., Hebblewhite, M., Mitchell, M., \& Matthiopoulos, J. (2010). The interpretation of habitat preference metrics under useavailability designs. Philos. Trans. R. Soc. B Biol. Sci. 365, 2245-2254.

Bolker, B. M., Brooks, M. E., Clark, C. J., Geange, S. W., Poulsen, J. R., Stevens, M. H. H., \& White, J.-S. S. (2009). Generalized linear mixed models: a practical guide for ecology and evolution. Trends Ecol. Evol. 24, 127-135.

Bouyer, Y., San Martin, G., Poncin, P., Beudels-Jamar, R. C., Odden, J., \& Linnell, J. D. (2015). Eurasian lynx habitat selection in human-modified landscape in Norway: Effects of different human habitat modifications and behavioral states. Biol. Conserv. 191, 291-299.

Boyce, M. S., Vernier, P. R., Nielsen, S. E., \& Schmiegelow, F. K. A. (2002). Evaluating resource selection functions. Ecol. Model. 157, 281-300.

Bryson-Morrison, N., Tzanopoulos, J., Matsuzawa, T., \& Humle, T. (2017). Activity and Habitat Use of Chimpanzees (Pan troglodytes verus) in the Anthropogenic Landscape of Bossou, Guinea, West Africa. Int. J. Primatol. 38, 282-302.

Calenge, C. (2006). The package adehabitat for the R software: a tool for the analysis of space and habitat use by animals. Ecol. Model. 197, 1035. 
515 Campbell, L. A. D. (2019). Fostering of a wild, injured, juvenile by a neighbouring group: implications for rehabilitation and release of Barbary macaques confiscated from illegal trade. Primates 60, 339-345.

Campbell, L. A. D., Tkaczynski, P. J., Lehmann, J., Mouna, M., \& Majolo, B. (2018). Social

Campbell, L. A. D., Tkaczynski, P. J., Mouna, M., Derrou, A., Oukannou, L., Majolo, B., \& van sleeping areas in an endangered primate: implications for habitat conservation. R. Soc. Open Sci. 5, 181113.

Campbell, L. A. D., Tkaczynski, P. J., Mouna, M., Qarro, M., Waterman, J., \& Majolo, B. (2016). Behavioral responses to injury and death in wild Barbary macaques (Macaca sylvanus). Primates 57, 309-315.

Camperio Ciani, A., \& Mouna, M. (2006). Human and environmental causes of the rapid decline of Macaca sylvanus in the Middle Atlas of Morocco. Barbary Macaque Biol. Manag. Conserv. Nottm. Univ. Press Nottm. 257-275.

Carne, C., Semple, S., MacLarnon, A., Majolo, B., \& Maréchal, L. (2017). Implications of TouristMacaque Interactions for Disease Transmission. EcoHealth 14, 704-717.

Ciani, A. C., Palentini, L., Arahou, M., Martinoli, L., Capiluppi, C., \& Mouna, M. (2005). Population decline of Macaca sylvanus in the middle atlas of Morocco. Biol. Conserv. 121, $635-641$.

Ciuti, S., Northrup, J. M., Muhly, T. B., Simi, S., Musiani, M., Pitt, J. A., \& Boyce, M. S. (2012). Effects of humans on behaviour of wildlife exceed those of natural predators in a landscape of fear. PloS One 7, e50611. 
Coleman, B. T., \& Hill, R. A. (2014). Living in a landscape of fear: the impact of predation, resource availability and habitat structure on primate range use. Anim. Behav. 88, 165-173.

Deag, J. M. (1975). A study of the social behaviour and ecology on the wild Barbary macaque, Macaca sylvanus (PhD Thesis). University of Bristol.

Donati, G., Campera, M., Balestri, M., Serra, V., Barresi, M., Schwitzer, C., Curtis, D. J., \& Santini, L. (2016). Ecological and Anthropogenic Correlates of Activity Patterns in Eulemur. Int. J. Primatol. 37, 29-46.

Ellis, E. C., \& Ramankutty, N. (2008). Putting people in the map: anthropogenic biomes of the world. Front. Ecol. Environ. 6, 439-447.

Fieberg, J., \& Kochanny, C. O. (2005). Quantifying home-range overlap: the importance of the utilization distribution. J. Wildl. Manag. 69, 1346-1359.

Fox, J., \& Monette, G. (1992). Generalized Collinearity Diagnostics. J. Am. Stat. Assoc. 87, 178183.

Frid, A., \& Dill, L. M. (2002). Human-caused Disturbance Stimuli as a Form of Predation Risk. Conserv. Ecol. 6.

Ganzhorn, J. U. (2003). Habitat description and phenology. Field Lab. Methods Primatol. 40-56.

Gaynor, K. M., Hojnowski, C. E., Carter, N. H., \& Brashares, J. S. (2018). The influence of human disturbance on wildlife nocturnality. Science 360, 1232-1235.

Gilchrist, J. S., \& Otali, E. (2002). The effects of refuse-feeding on home-range use, group size, and intergroup encounters in the banded mongoose. Can. J. Zool. 80, 1795-1802.

Gill, J. A. (2000). Predicting the consequences of human disturbance from behavioral decisions. Behav. Conserv. 55-64.

Guillemain, M., Blanc, R., Lucas, C., \& Lepley, M. (2007). Ecotourism disturbance to wildfowl in protected areas: historical, empirical and experimental approaches in the Camargue, Southern France. In Biodivers. Conserv. Eur. pp. 391-409. Springer. 
Hanya, G., Ménard, N., Qarro, M., Ibn Tattou, M., Fuse, M., Vallet, D., Yamada, A., Go, M., Takafumi, H., Tsujino, R., Agetsuma, N., \& Wada, K. (2011). Dietary adaptations of temperate primates: comparisons of Japanese and Barbary macaques. Primates 52, 187-198.

Hebblewhite, M., \& Merrill, E. (2008). Modelling wildlife-human relationships for social species with mixed-effects resource selection models: Mixed-effect resource selection models. $J$. Appl. Ecol. 45, 834-844.

Hockings, K. J., Anderson, J. R., \& Matsuzawa, T. (2006). Road crossing in chimpanzees: A risky business. Curr. Biol. 16, R668-R670.

Hockings, K. J., Anderson, J. R., \& Matsuzawa, T. (2012). Socioecological adaptations by chimpanzees, Pan troglodytes verus, inhabiting an anthropogenically impacted habitat. Anim. Behav. 83, 801-810.

Horne, J. S., Garton, E. O., Krone, S. M., \& Lewis, J. S. (2007). ANALYZING ANIMAL MOVEMENTS USING BROWNIAN BRIDGES. Ecology 88, 2354-2363.

Krief, S., Cibot, M., Bortolamiol, S., Seguya, A., Krief, J.-M., \& Masi, S. (2014). Wild chimpanzees on the edge: nocturnal activities in croplands. PLoS One 9, e109925.

Laundré, J. W., Hernández, L., \& Ripple, W. J. (2010). The landscape of fear: ecological implications of being afraid. Open Ecol. J. 3, 1-7.

Lima, S. L., \& Dill, L. M. (1990). Behavioral decisions made under the risk of predation: a review and prospectus. Can. J. Zool. 68, 619-640.

Lowry, H., Lill, A., \& Wong, B. B. M. (2013). Behavioural responses of wildlife to urban environments: Behavioural responses to urban environments. Biol. Rev. 88, 537-549.

Luke, S. G. (2017). Evaluating significance in linear mixed-effects models in R. Behav. Res. Methods 49, 1494-1502.

Majolo, B., McFarland, R., Young, C., \& Qarro, M. (2013). The Effect of Climatic Factors on the Activity Budgets of Barbary Macaques (Macaca sylvanus). Int. J. Primatol. 34, 500-514. 
Manly, B. F. J., McDonald, L. L., Thomas, D. L., McDonald, T. L., \& Erickson, W. P. (2002). Resource selection by animals: statistical analysis and design for field studies. Nord. Neth. Kluwer.

Maréchal, L., MacLarnon, A., Majolo, B., \& Semple, S. (2016). Primates’ behavioural responses to tourists: evidence for a trade-off between potential risks and benefits. Sci. Rep. 6, 32465.

Maréchal, L., Semple, S., Majolo, B., \& MacLarnon, A. (2016). Assessing the Effects of Tourist Provisioning on the Health of Wild Barbary Macaques in Morocco. (B.-S. Yue, Ed.)PLOS ONE 11, e 0155920.

Maréchal, L., Semple, S., Majolo, B., Qarro, M., Heistermann, M., \& MacLarnon, A. (2011). Impacts of tourism on anxiety and physiological stress levels in wild male Barbary macaques. Biol. Conserv. 144, 2188-2193.

Martin, J., Basille, M., Van Moorter, B., Kindberg, J., Allainé, D., \& Swenson, J. E. (2010). Coping with human disturbance: spatial and temporal tactics of the brown bear ( Ursus arctos ). Can. J. Zool. 88, 875-883.

McGraw, W. S., Plavcan, J. M., \& Adachi-Kanazawa, K. (2002). Adult female Cercopithecus diana employ canine teeth to kill another adult female C. diana. Int. J. Primatol. 23, 1301-1308.

McKinney, T. (2011). The effects of provisioning and crop-raiding on the diet and foraging activities of human-commensal white-faced Capuchins (Cebus capucinus). Am. J. Primatol. 73, 439-448.

Mehlman, P. T. (1984). Aspects of the ecology and conservation of the Barbary macaque in the fir forest habitat of the Moroccan Rif Mountains. In Barbary Macaque. pp. 165-199. Springer.

Mehlman, P. T., \& Parkhill, R. S. (1988). Intergroup interactions in wild Barbary macaques (Macaca sylvanus), Ghomaran Rif mountains, Morocco. Am. J. Primatol. 15, 31-44.

Ménard, N. (2002). Ecological plasticity of Barbary macaques (Macaca sylvanus). Evol. Anthropol. Issues News Rev. 11, 95-100. 
Ménard, N., \& Qarro, M. (1999). Bark stripping and water availability: a comparative study between Moroccan and Algerian Barbary macaques (Macaca sylvanus).

Ménard, N., Rantier, Y., Foulquier, A., Qarro, M., Chillasse, L., Vallet, D., Pierre, J.-S., \& Butet, A. (2014). Impact of human pressure and forest fragmentation on the Endangered Barbary macaque Macaca sylvanus in the Middle Atlas of Morocco. Oryx 48, 276-284.

Mun, J. S. C. (2014). Ecology of Long-Tailed Macaques (Macaca fascicularis) and its Implication for the Management of Human-Macaque Interface in Singapore 191.

Myneni, R. B., Hall, F. G., Sellers, P. J., \& Marshak, A. L. (1995). The interpretation of spectral vegetation indexes. IEEE Trans. Geosci. Remote Sens. 33, 481-486.

Nielson, R. M., \& Sawyer, H. (2013). Estimating resource selection with count data. Ecol. Evol. 3, 2233-2240.

Nowak, K., Wimberger, K., Richards, S. A., Hill, R. A., \& le Roux, A. (2017). Samango Monkeys (Cercopithecus albogularis labiatus) Manage Risk in a Highly Seasonal, Human-Modified Landscape in Amathole Mountains, South Africa. Int. J. Primatol. 38, 194-206.

Oriol-Cotterill, A., Macdonald, D. W., Valeix, M., Ekwanga, S., \& Frank, L. G. (2015). Spatiotemporal patterns of lion space use in a human-dominated landscape. Anim. Behav. 101, 27-39.

Payne, H. F. P., Lawes, M. J., \& Henzi, S. P. (2003). Fatal Attack on an Adult Female Cercopithecus mitis erythrarchus: Implications for Female Dispersal in Female-Bonded Societies. Int. J. Primatol. 24, 1245-1250.

R Core Team. (2019). R: A Language and Environment for Statistical Computing. Vienna, Austria: R Foundation for Statistical Computing.

Rare and The Behavioural Insights Team. (2019). Behaviour Change For Nature: A Behavioural Science Toolkit For Practitioners. p. 84. Arlington, VA: Rare.

Russon, A. E., \& Wallis, J. (2014). Primate Tourism. Cambridge University Press. 
639 Schaik, C. P. van. (2013). The costs and benefits of flexibility as an expression of behavioural plasticity: a primate perspective. Philos. Trans. R. Soc. Lond. B Biol. Sci. 368, 20120339.

641 Scheffrahn, W., Ménard, N., Vallet, D., \& Gaci, B. (1993). Ecology, demography, and population genetics of Barbary macaques in Algeria. Primates 34, 381-394.

643 Sih, A., Ferrari, M. C., \& Harris, D. J. (2011). Evolution and behavioural responses to humaninduced rapid environmental change. Evol. Appl. 4, 367-387.

Silva-Rodríguez, E. A., \& Sieving, K. E. (2012). Domestic dogs shape the landscape-scale distribution of a threatened forest ungulate. Biol. Conserv. 150, 103-110.

Singmann, H., Bolker, B., Westfall, J., \& Aust, F. (2017). afex: Analysis of Factorial Experiments. R Package Version.

Steg, L. (2016). Values, Norms, and Intrinsic Motivation to Act Proenvironmentally. Annu. Rev.

St. John, F. A. V., Keane, A. M., Jones, J. P. G., \& Milner-Gulland, E. J. (2014). FORUM: Robust study design is as important on the social as it is on the ecological side of applied ecological Environ. Resour. 41, 277-292.

Swets, J. A. (1988). Measuring the accuracy of diagnostic systems. Science 240, 1285-1293.

Thomas, D. L., Buckland, S. T., Rexstad, E. A., Laake, J. L., Strindberg, S., Hedley, S. L., Bishop, J. R. B., Marques, T. A., \& Burnham, K. P. (2010). Distance software: design and analysis of distance sampling surveys for estimating population size. J. Appl. Ecol. 47, 5-14.

Thomas, D. L., \& Taylor, E. J. (1990). Study Designs and Tests for Comparing Resource Use and Availability. J. Wildl. Manag. 54, 322-330.

Toutin, T. (2008). ASTER DEMs for geomatic and geoscientific applications: a review. Int. J. Remote Sens. 29, 1855-1875.

Wang, Q., Adiku, S., Tenhunen, J., \& Granier, A. (2005). On the relationship of NDVI with leaf 663 area index in a deciduous forest site. Remote Sens. Environ. 94, 244-255. 
664 Waterman, J. (2016). Human-macaque encounters in Ifrane National Park, Morocco. Behavioural, spatial, and temporal coping strategies of the Barbary macaque (Macaca sylvanus) (Unpublished MSc Thesis). University of Lincoln, Lincoln.

667 Waters, S., Harrad, A. E., Chetuan, M., Bell, S., \& Setchell, J. M. (2017). Dogs Disrupting Wildlife:

668 Domestic Dogs Harass and Kill Barbary Macaques in Bouhachem Forest, Northern $669 \quad$ Morocco 5.

670 Wilson, R. R., Gilbert-Norton, L., \& Gese, E. M. (2012). Beyond use versus availability: behaviour671 explicit resource selection. Wildl. Biol. 18, 424-430.

672 Woodroffe, R., Thirgood, S., \& Rabinowitz, A. (2005). People and wildlife, conflict or coexistence? Cambridge University Press.

674 Wrangham, R. W., Crofoot, M., Lundy, R., \& Gilby, I. (2007). Use of Overlap Zones among 675 Group-Living Primates: A Test of the Risk Hypothesis. Behaviour 144, 1599-1619.

676 Wrangham, R. W., Wilson, M. L., \& Muller, M. N. (2006). Comparative rates of violence in 677 chimpanzees and humans. Primates 47, 14-26. 
679 Table 1. Predictors included in resource selection functions.

\begin{tabular}{|c|c|c|c|}
\hline Characteristic & Variable description & $\begin{array}{l}\text { Variable } \\
\text { type }\end{array}$ & Range \\
\hline \multirow[t]{2}{*}{ Anthropogenic } & Distance from herding route & Continuous & $0-1595 \mathrm{~m}$ \\
\hline & Distance from road & Continuous & $0-1788 \mathrm{~m}$ \\
\hline \multirow[t]{3}{*}{ Natural } & Forest cover & Discrete & open, moderate, dense \\
\hline & Ecological productivity (NDVI) & Continuous & $0.012-0.42$ \\
\hline & Slope & Continuous & $0.74-41.47$ \\
\hline Social & Home range overlap & Discrete & $\begin{array}{l}\text { not overlapping, } \\
\text { overlapping }\end{array}$ \\
\hline Temporal & Season & Discrete & $\begin{array}{l}\text { spring, summer, } \\
\text { autumn, winter }\end{array}$ \\
\hline \multirow[t]{2}{*}{ Control } & $\begin{array}{l}\text { Length of herding routes } \\
\text { (per } \mathrm{km}^{2} \text { of home range) }\end{array}$ & Continuous & $0.23-2.84 \mathrm{~km}$ \\
\hline & $\begin{array}{l}\text { length of roads (per } \mathrm{km}^{2} \text { of home } \\
\text { range) }\end{array}$ & Continuous & $0.63-1.65 \mathrm{~km}$ \\
\hline
\end{tabular}


681 Table 2. Results of the generalized linear mixed model. Statistically significant $(\alpha=0.05) p$-values are 682 in bold and underlined.

\begin{tabular}{lcccc}
\hline Variable & \multicolumn{4}{c}{ Parameter } \\
& $\beta$ & SE & $Z$ & $P$ \\
\hline Intercept & -3.101 & 0.175 & -17.757 & $\underline{\mathbf{0 0 . 0 0 1}}$ \\
Cover-Dense & 0.290 & 0.112 & 2.586 & $\mathbf{0 . 0 1 0}$ \\
Cover-Open & -0.995 & 0.142 & -6.998 & $\underline{\mathbf{0 . 0 0 1}}$ \\
Home Range Overlap (1) & 0.252 & 0.061 & 4.147 & $\underline{\mathbf{0 . 0 0 1}}$ \\
Slope & -0.016 & 0.029 & -0.547 & 0.584 \\
Herding route density & 0.056 & 0.148 & 0.379 & 0.704 \\
Road density & -0.235 & 0.126 & -1.86 & 0.0632 \\
Productivity (NDVI) & 0.081 & 0.058 & 1.393 & 0.163 \\
Distance-from-herding route & -0.584 & 0.135 & -4.33 & $\leq \mathbf{0 . 0 0 1}$ \\
Season (Summer) & -0.110 & 0.070 & -1.562 & 0.118 \\
Season (Autumn) & 0.027 & 0.090 & 0.295 & 0.768 \\
Season (Winter) & 0.078 & 0.119 & 0.659 & 0.510 \\
Distance-from-road & -0.392 & 0.318 & -1.233 & 0.218 \\
Distance-from-herding route (Summer) & 0.412 & 0.066 & 6.213 & $\leq \mathbf{0 . 0 0 1}$ \\
Distance-from-herding route (Autumn) & 0.022 & 0.092 & 0.235 & 0.814 \\
Distance-from-herding route (Winter) & 0.006 & 0.095 & 0.061 & 0.951 \\
Distance-from-road (Summer) & -0.374 & 0.062 & -6.008 & $\leq \mathbf{0 . 0 0 1}$ \\
Distance-from-road (Autumn) & -0.620 & 0.091 & -6.802 & $\underline{\mathbf{0 . 0 0 1}}$ \\
Distance-from-road (Winter) & -0.435 & 0.088 & -4.935 & $\mathbf{\leq \mathbf { 0 . 0 0 1 }}$ \\
\hline Random effects & Variance & Std. deviation \\
Group & 0.076 & 0.275 \\
Group (Distance-from-herding route) & 0.070 & 0.264 \\
Group (Distance-from-road) & 0.486 & 0.697 \\
\hline
\end{tabular}


684 Table 3: Results of the likelihood ratio test (type 3 tests) for the generalized linear mixed model.

685 Statistically significant $(\alpha=0.05) p$-values are underlined.

\begin{tabular}{lccc}
\hline Variable & \multicolumn{3}{c}{ Parameters } \\
\hline & df & Chisq & $P$ \\
Cover & 2 & 168.58 & $\underline{\mathbf{0 . 0 0 0 1}}$ \\
Home range overlap & 1 & 16.98 & $\underline{\mathbf{< 0 . 0 0 0 1}}$ \\
Slope & 1 & 0.30 & 0.580 \\
Herding route density & 1 & 0.14 & 0.710 \\
Road density & 1 & 2.64 & 0.100 \\
Productivity (NDVI) & 1 & 1.94 & 0.160 \\
Distance-from-herding route & 1 & 6.72 & 0.010 \\
Season & 3 & 2.69 & 0.440 \\
Distance-from-road & 1 & 3.80 & 0.050 \\
Distance-from-herding route $*$ Season & 3 & 47.92 & $\leq \mathbf{0 . 0 0 0 1}$ \\
Distance-from-road $*$ Season & 3 & 77.08 & $\underline{\mathbf{0 . 0 0 0 1}}$ \\
\hline
\end{tabular}

686 
Table 4. Descriptive summary of statistically significant habitat selection preferences.

688

\begin{tabular}{|c|c|c|}
\hline $\begin{array}{l}\text { Landscape } \\
\text { feature }\end{array}$ & Response & Interpretation \\
\hline Cover & $\begin{array}{l}\text { Select areas of dense } \\
\text { and moderate cover. } \\
\text { Avoid open areas }\end{array}$ & $\begin{array}{l}\text { Open areas lack cover; this limits escape possibilities, } \\
\text { given that macaques usually climb trees to avoid dogs; } \\
\text { their primary predators in this study site. }\end{array}$ \\
\hline $\begin{array}{l}\text { Home Range } \\
\text { Overlap }\end{array}$ & $\begin{array}{l}\text { Greater use of areas } \\
\text { of home range } \\
\text { overlap }\end{array}$ & $\begin{array}{l}\text { Macaque home ranges overlap in key locations: areas of } \\
\text { high natural productivity, and areas close to roads. } \\
\text { Multiple groups inhabit a shrinking home range fragment } \\
\text { and must share/compete for use of these profitable areas. }\end{array}$ \\
\hline $\begin{array}{l}\text { Herding } \\
\text { Routes }\end{array}$ & Avoid in Summer & $\begin{array}{l}\text { Macaques avoid areas used by local shepherds, to reduce } \\
\text { the risk of being attacked by their dogs. }\end{array}$ \\
\hline Roads & $\begin{array}{l}\text { Avoid in Spring. } \\
\text { Select in Autumn, } \\
\text { and to a lesser extent } \\
\text { in Winter }\end{array}$ & $\begin{array}{l}\text { Macaques avoid roads in Spring when natural food is } \\
\text { abundant, and approach roads in Autumn and Winter (as } \\
\text { natural food availability declines and road traffic peaks) } \\
\text { to increase the chances of being provisioned by tourists. }\end{array}$ \\
\hline
\end{tabular}

689

690

691 
692 Table 5. Values of the utilization distribution overlap index (UDOI) for Barbary macaque groups

693 comparing home-range overlap between different groups and seasons.

694

\begin{tabular}{lllllllr}
\hline Group Pairs & $\begin{array}{l}\text { All } \\
\text { Seasons }\end{array}$ & $\begin{array}{l}\text { Spring } \\
\mathbf{2 0 1 3}\end{array}$ & $\begin{array}{l}\text { Summer } \\
\mathbf{2 0 1 3}\end{array}$ & $\begin{array}{l}\text { Autumn } \\
\mathbf{2 0 1 3}\end{array}$ & $\begin{array}{l}\text { Winter } \\
\mathbf{2 0 1 3}-\end{array}$ & $\begin{array}{l}\text { Spring } \\
\mathbf{2 0 1 4}\end{array}$ \\
& & & & & $\mathbf{2 0 1 4}$ & & \\
\hline Blue-Green & 0 & 0 & 0.045 & 0 & 0 & 0 & 696 \\
Blue-Purple & 0 & 0 & 0 & 0 & 0 & 0 & \\
Blue-Red & 0.006 & 0.001 & 0.050 & - & - & - & 697 \\
Blue-Yellow & 0.095 & 0.201 & 0.208 & 0 & 0 & 0.186 \\
Green-Purple & 0.153 & 0 & 0.057 & 0.012 & 0.655 & 0 & 698 \\
Green-Red & 0.042 & 0 & 0.072 & - & - & - & \\
Green- & 0 & 0 & 0.002 & 0 & 0 & 0 & 699 \\
Yellow & & & & & & & \\
Purple-Red & 0.366 & 0.552 & 0.118 & - & - & - & 700 \\
Purple- & 0 & 0.010 & 0 & 0 & 0 & 0 & \\
Yellow & & & & & & & \\
Red-Yellow & 0.067 & 0.247 & 0.061 & - & - & - & \\
\hline
\end{tabular}


Figures

718 Figure 1. Map showing the geographic location of the field site, the home range of the study groups 719 and the location of major anthropogenic features within the study site. Basemap source: Natural

720 Earth Data (2017)
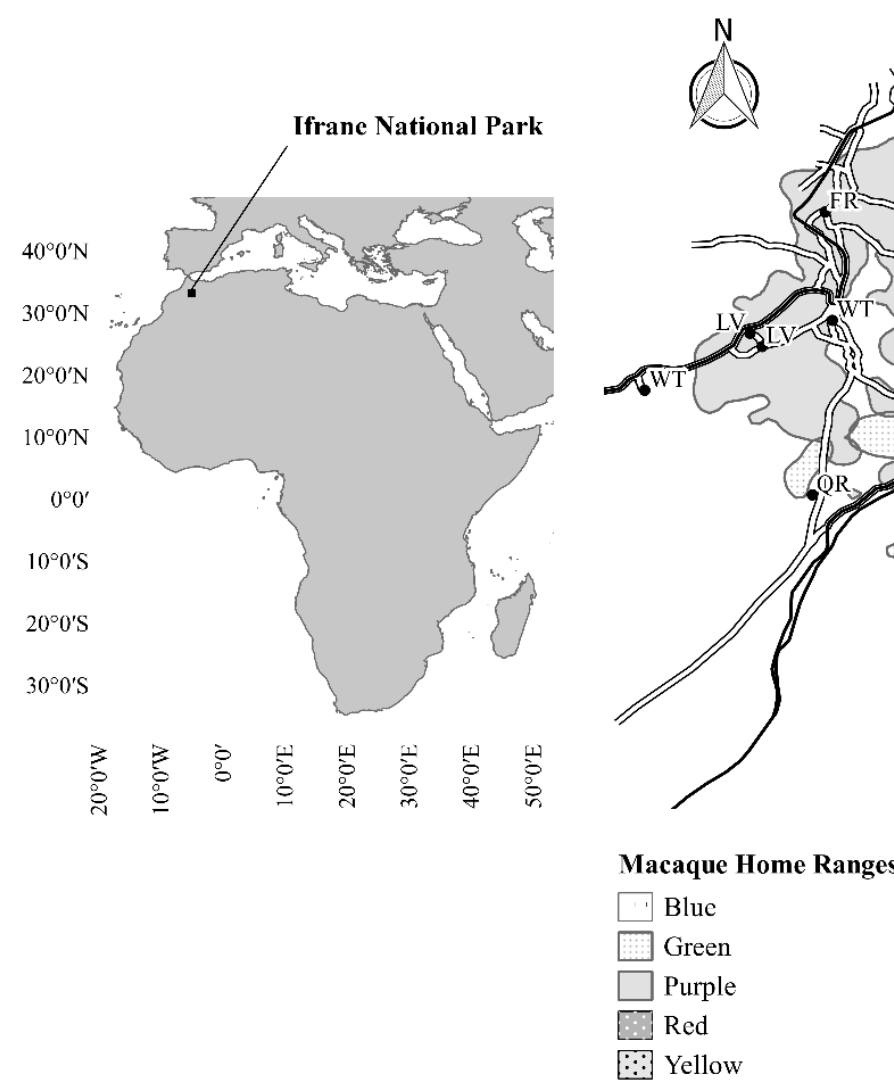
723 Figure 2. Seasonal variation in (a) mean NDVI, (b) traffic volume, and (c) herding route activity.

724 All seasons differed significantly from each other. Error bars represent standard errors.

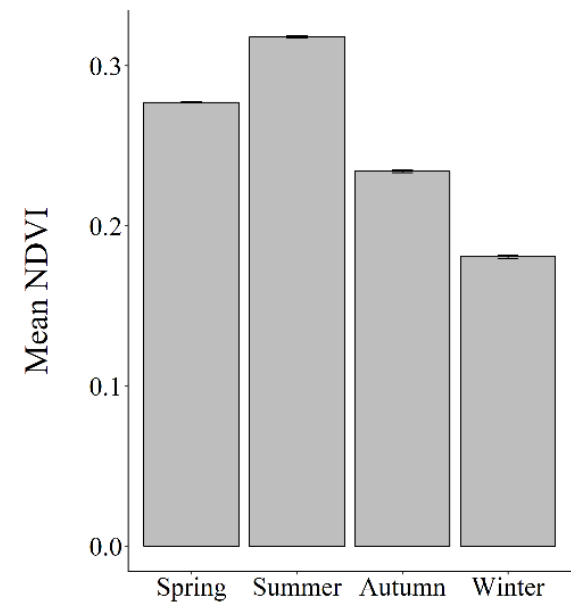

Season

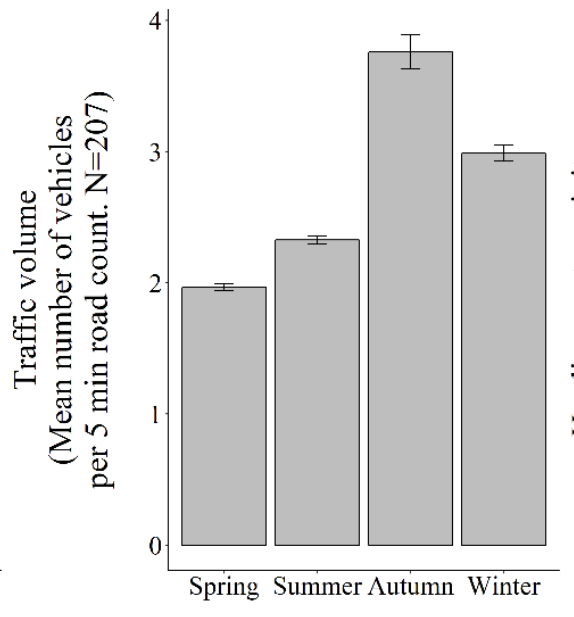

Season

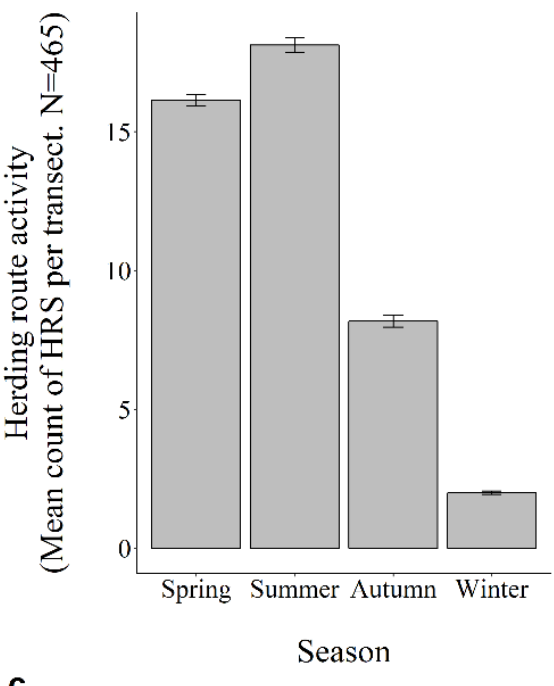

C 
727 Figure 3. Variation in median (a) NDVI, (b) distance from herding routes, and (c) distance from 728 roads by home range overlap. All variables differed significantly by home range overlap status.

729 Boxplots represent 25th and 75th percentiles, the inter-quartile range (IQR), center line indicates the 730 median, whiskers extend to the furthest data point that is within 1.5 times the IQR, and dots are 731 outliers. If the notches do not overlap, this is evidence that the medians are different.

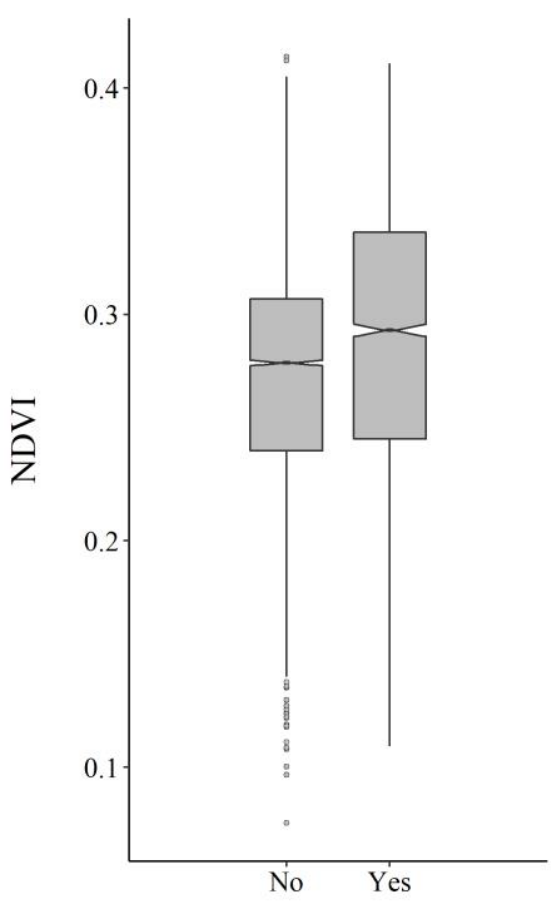

732

a Area of home range overlap

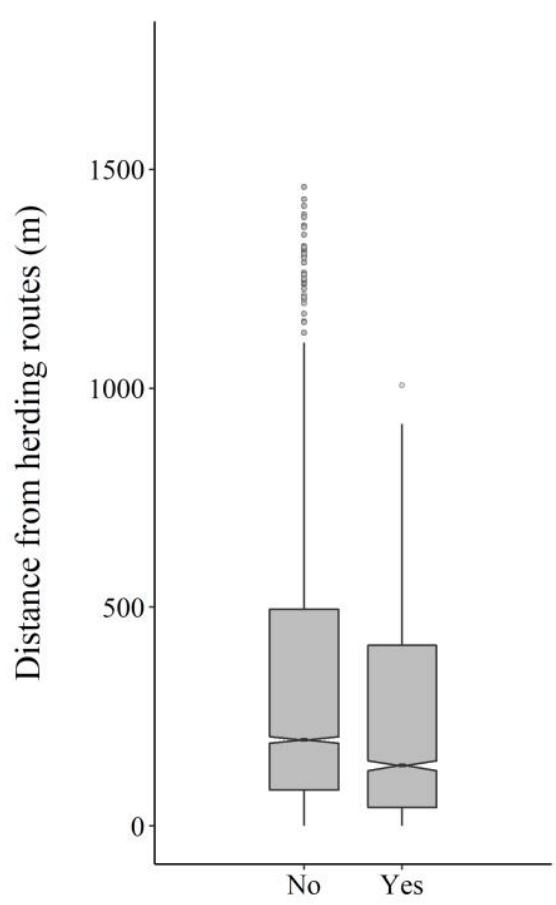

b

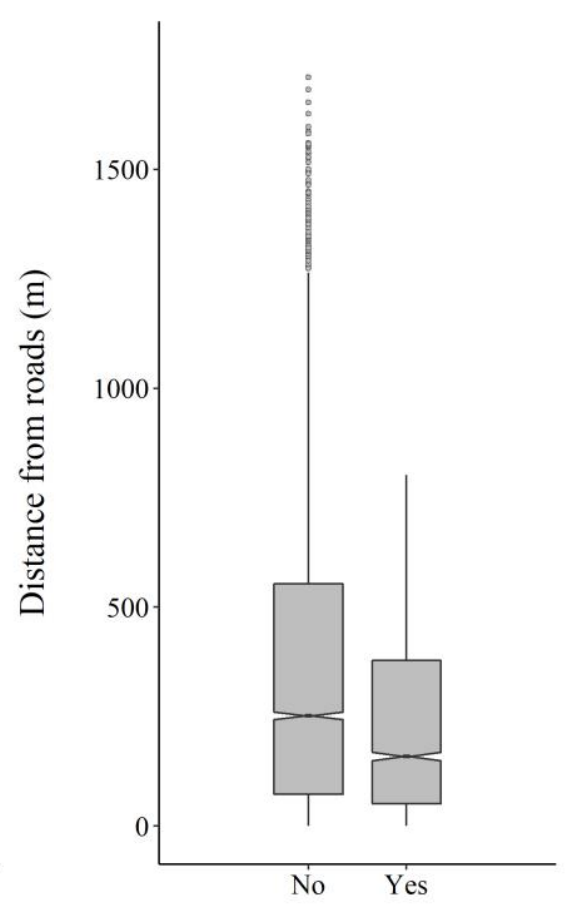

Area of home range overlap 
735 Figure 4. Predicted probability of a location being 'used' in relation to (a) herding route and (b)

736 road proximity.
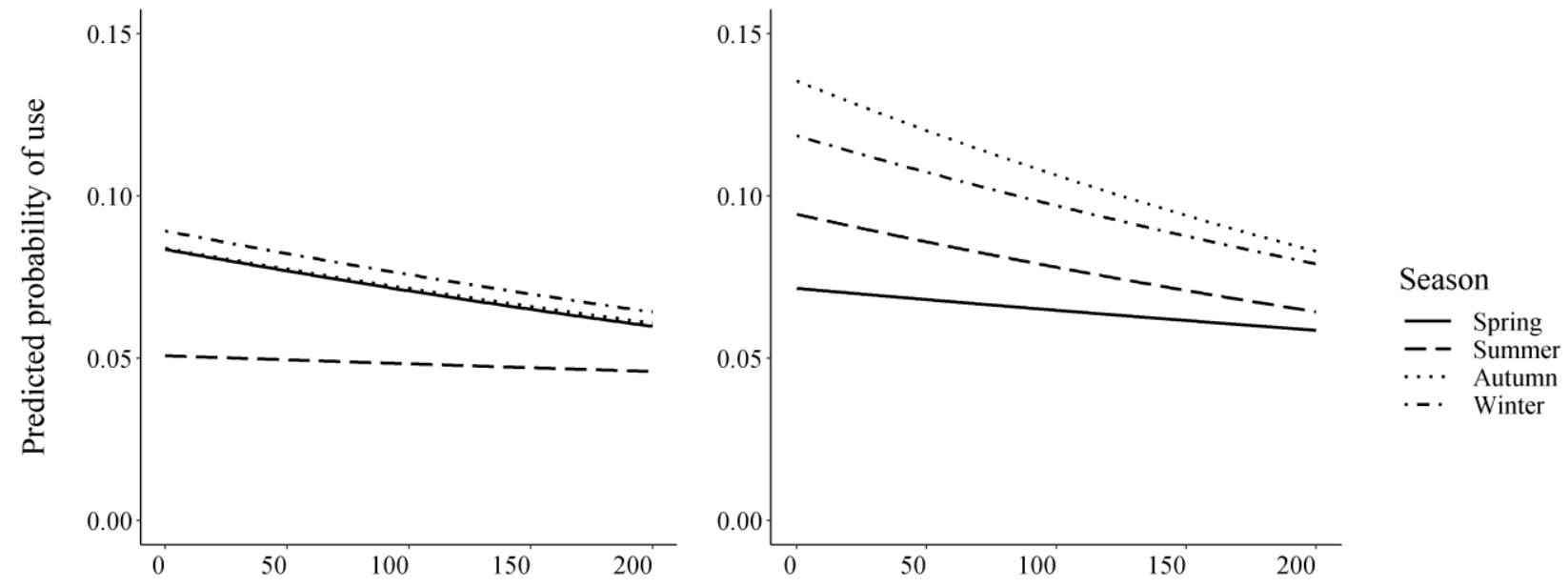

Distance from roads (m) 